ARTIGO ORIGINAL

\title{
Proposta metodológica para subsidiar conservação e melhoramento genético da erva mate no sul do Brasil, baseada em grupos climáticos
}

\author{
Methodological proposal, based on climate groups, for subsidizing \\ conservation and genetic improvement of yerba mate in southern Brazil \\ Elenice Fritzsons ${ }^{1}$ (1), Marcos Silveira Wrege ${ }^{1}$ (D), Marcia Toffani Simões Soares ${ }^{1}$ (D), \\ Ananda Virginia de Aguiar ${ }^{1}$ (D), Valderês Aparecida de Sousa ${ }^{1}$ (D), Andressa Godinho Scarante ${ }^{2}$ (D), \\ Maria de Fátima Matos Ambrósio 2 (1) \\ ${ }^{1}$ Embrapa Florestas, Colombo, PR, Brasil \\ ²Pontifícia Universidade Católica do Paraná - PUC-PR, Curitiba, PR, Brasil
}

Como citar: Fritzsons, E., Wrege, M. S., Soares, M. T. S., Aguiar, A. V., Sousa, V. A., Scarante, A. G., \& Ambrósio, M. F. M. (2020). Proposta metodológica para subsidiar conservação e melhoramento genético da erva mate no sul do Brasil, baseada em grupos climáticos. Scientia Forestalis, 48(128), e3267.

https://doi.org/10.18671/scifor.v48n128.22

\begin{abstract}
Resumo
Além de interferir no fenótipo das plantas, o clima atua como uma grande força seletiva que interfere no genótipo e direciona a variação genética entre as populações e, por isso, deve ser considerado ao se explorar a variabilidade genética em programas de conservação e melhoramento. O objetivo deste trabalho foi determinar grupos climáticos onde a erva-mate (Ilex paraguariensis S.T. Hill) ocorre naturalmente no sul do Brasil. Para isto foi montada uma base de dados com 195 ocorrências. Os dados foram submetidos à análise multivariada, georreferenciamento e modelagem. Foram identificados, espacialmente, quatro grupos utilizando 11 parâmetros climáticos e também altitude. Embora os grupos apresentem contiguidade espacial, foi verificado que a erva-mate ocorre em vários substratos litológicos e em diferentes ecossistemas (Floresta Ombrófila Mista, Floresta Ombrófila Densa Montana, Floresta Estacional Decidual e Semidecidual e os biomas Pampa e Mata Atlântica). Esta adaptação indica uma grande plasticidade adaptativa da erva-mate, bem maior que a da Araucária, espécie companheira da erva mate em muitos ecossistemas. Os grupos isolados podem pertencer a populações geneticamente distintas. Os resultados destes estudos podem ser utilizados para apoiar programas de melhoramento e conservação de espécies, uso atual e futuro, considerando as mudanças climáticas e as pressões antrópicas.
\end{abstract}

Palavras-chave: Análise multivariada; Mudança climática; Conservação de espécies; Plasticidade adaptativa.

\begin{abstract}
In addition to interfering with plant phenotype, climate acts as a major selective force that affects the plant's genotype and shapes genetic variation between populations. Thus, it should be considered when exploring this genetic variability in conservation and breeding programs. The aim of this work was to determine differences between specific climates where yerba mate occurs naturally in southern Brazil. A database of 195 natural occurrences of yerba mate was set up. These data was applied to multivariate analysis, georeferencing and modelling. Four climatic groups were obtained using eleven climatic parameters in addition to altitude. Although these groups feature spatial geographic contiguity, it was found that yerba mate occurs in several lithologic substrates, in different ecosystems (Mixed Ombrophylous Forest, Ombrophylous Dense Montane Forest, Deciduous and Semi-deciduous Seasonal
\end{abstract}

Fonte de financiamento: Nenhuma.

Conflito de interesse: Nada a declarar.

Autor correspondente: elenice.fritzsons@embrapa.br

Recebido: 31 janeiro 2019.

Aceito: 25 novembro 2019

Editor: Paulo Henrique Müller Silva.

cc (i) Este é um artigo publicado em acesso aberto (Open Access) sob a licença Creative Commons Attribution, que permite uso, distribuição e reprodução em qualquer meio, sem restrições desde que o trabalho original seja corretamente citado. 
Forest, Atlantic Forest biome and in the Pampa biome). This adaptation indicates a wide adaptive plasticity of yerba mate, much larger than that of Araucaria, which is a species that occurs together with yerba mate in many ecosystems. Isolated groups can be used in genetic studies to check whether populations are also genetically distinct. The output of this study may be used to support breeding and conservation programs, for current and for future use, considering the climatic changes and the anthropic pressures.

Keywords: Multivariate analysis; Climate; Species conservation; Adaptive plasticity.

\section{INTRODUÇÃO}

Há muito tempo sabe se que o clima desempenha um papel fundamental no fenótipo das plantas: no curto prazo, de forma direta, via efeitos ambientais que interferem na sobrevivência, crescimento e reprodução e, no longo prazo, atua como uma grande força seletiva que afeta o genótipo da planta. A seleção natural relacionada ao clima leva à adaptação local e à diferenciação das populações arbórea s ao longo de gradientes climáticos (Howe et al., 2003; Wang et al., 2010). Na verdade, a variabilidade genética possibilita diferentes respostas adaptativas das populações aos efeitos ambientais.

Desta forma, a possibilidade de se encontrar variações genéticas entre populações distribuídas em uma ampla região geográfica, com climas e microclimas distintos, é maior do que naquelas populações com ocorrência restrita a locais mais homogêneos (Martins et al., 2018). Assim, identificar as associações entre climas homogêneos e populações e, também, as variáveis climáticas de maior relevância para a adaptação de uma determinada espécie (ou população), é fundamental para se estabelecer estratégias para a conservação das espécies (ou populações) em áreas naturais. Esta informação é também útil para indicar locais mais adequados ao plantio de determinadas espécies ou populações, sendo esta a base do zoneamento climático (Wrege et al., 2018).

A erva-mate (Ilex paraguariensis S. T. Hill) é sensível à influência do clima, especialmente no que se refere à taxa de crescimento em altura, diâmetro e produção de massa foliar. A fenologia reprodutiva também é afetada, pois a floração da erva-mate varia de acordo com a região de ocorrência; de setembro a outubro no Rio Grande do Sul; de setembro a novembro no Paraná; de setembro a dezembro em Santa Catarina e, em novembro, no Estado de São Paulo (Carvalho, 2003; Morellato, 2007).

Vieira et al. (2003), constataram a influência de parâmetros climáticos sobre o desenvolvimento vegetativo da erva mate e a radiação solar foi o parâmetro que exerceu maior influência na área foliar e produção de fitomassa da erva mate. Os efeitos microclimáticos influenciaram no crescimento das plantas, independente do estádio de desenvolvimento.

A erva-mate ocorre, naturalmente, em três países da América do Sul: Brasil, Paraguai e Argentina. Porém, o Brasil possui maior parte da área de distribuição da espécie, em torno de $80 \%$, sendo restrita a cinco estados brasileiros: Rio Grande do Sul, Santa Catarina, Paraná, São Paulo e Mato Grosso do Sul (Maccari \& Santos, 2000). A erva-mate em sua área de ocorrência

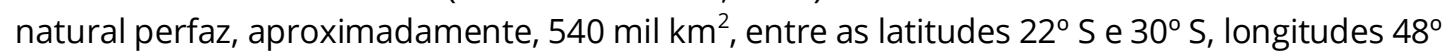
$30^{\prime} \mathrm{W}$ e $56^{\circ} 10^{\prime} \mathrm{W}$ e altitudes entre 500 a 1500 metros acima do nível do mar, com temperaturas médias anuais entre $15^{\circ} \mathrm{C}$ a $18^{\circ} \mathrm{C}$, sendo as geadas frequentes ou pouco frequentes (Rotta \& Oliveira, 2007), em clima com predominância Cfb (clima temperado) e Cfa (clima subtropical) (classificação de Köeppen). A precipitação média anual está em torno de $1.500 \mathrm{~mm}$.

Os solos onde a erva-mate é encontrada são altamente ácidos ( $\mathrm{pH}-\mathrm{CaCl} 23.7$ a 4.9), o que indica que a espécie é tolerante a esta condição extrema, especialmente em relação à toxicidade do alumínio (Reissmann et al., 1999). Para a erva-mate, a calagem deve visar o suprimento de Ca e Mg para as plantas e não a correção da acidez do solo, para neutralizar o Al trocável (Santin et al., 2013). Entretanto, a condição de solos pobres não define a distribuição da espécie, pois a erva-mate ocorre também em solos mais férteis, acompanhando a distribuição natural da araucária. Resende et al. (1988), afirmou que a 
espécie prefere solos medianamente profundos a profundos, praticamente não ocorrendo em solos rasos, como os Neossolos Litólicos.

Vários produtos são obtidos da erva-mate, sendo de uso primário as folhas e, secundário, a madeira, para a produção de lâmina, e os componentes químicos como alcalóides, taninos e compostos sapônicos (Carvalho, 2003). Entre os alcalóides de maior interesse, destacam-se a cafeína, a teofilina e a teobromina, os quais são usados como calmantes, sedativos, estimulantes e analgésicos.

A erva-mate é muito utilizada como bebida, como "chimarrão" ou "tererê", porém a espécie também é muito empregada no paisagismo, para recuperação de áreas degradadas e restauração de mata ciliar, em locais sem problemas de drenagem, e para compor sistemas agroflorestais consorciados com outras espécies perenes e anuais (Antoniazzi et al., 2018).

\section{Objetivos}

O objetivo da pesquisa foi identificar e caracterizar os grupos de clima homogêneos onde ocorre naturalmente a erva-mate na região sul do Brasil, discriminando parâmetros climáticos que estão associados à distribuição destes grupos.

Esta informação é importante para dar subsídios aos programas de conservação genética e ao uso da espécie em melhoramento. Para programas de conservação e melhoramento genético, zonas climáticas devem ser priorizadas com a finalidade de manutenção e representação da diversidade genética da espécie. As informações geradas nesse trabalho podem evitar a sobreposição de coleta de dados e instalação de áreas experimentais em regiões climaticamente semelhantes e, com isto, reduzir gastos e dar subsídios para o melhoramento e conservação da espécie, para o presente e futuro, considerando se também os efeitos das mudanças climáticas globais (Luedeling, 2012).

\section{MATERIAL E MÉTODOS}

\section{Obtenção de dados}

Foram usadas três fontes distintas de dados uma fonte primária e outras duas fontes secundárias. Para compor a fonte primária, diversas regiões de ocorrência da espécie foram amostradas em campo, principalmente nos estados do Rio Grande do Sul e do Paraná. No Rio Grande do Sul, foi registrado o limite sul de ocorrência natural da erva-mate. Os levantamentos foram feitos em Florestas Nacionais - FLONAs, em populações naturais, ou nas áreas de reserva natural em propriedades particulares (RPPN).

Para os dados secundários, foi utilizada a ferramenta SpeciesLink, do banco de dados de coleções biológicas do Centro de Referência em Informação Ambiental - CRIA (Biota, 1999), que reúne informações históricas de vários herbários. Estes dados foram analisados e consistidos, eliminando-se os elementos discrepantes, fora do padrão, dados duplicados, pontos com coordenadas invertidas e outras situações.

Além do banco de dados do CRIA, o conjunto de pontos de ocorrência de erva-mate foi complementado com dados de literatura, a partir de uma revisão sistemática de registro de ocorrência em documentos científicos publicados em revistas indexadas, teses e dissertações (ESALQ/USP, UNESP, UFPR). Foram selecionados apenas os indivíduos que apresentavam coordenadas geográficas originais dos locais de coleta.

\section{Levantamento das variáveis climáticas}

Os atributos climáticos considerados foram: o coeficiente de variação da precipitação pluvial; média das precipitações acumuladas nas estações do ano (primavera, verão, outono e inverno); do mês mais frio do ano (julho); do mês mais quente do ano (janeiro);somatório do número de horas de frio abaixo de $7,2^{\circ} \mathrm{C}$ acumulado no período outono-inverno; risco de geada; desvio padrão das temperaturas mínima e máxima; isotermalidade; média anual das temperaturas mínimas; do mês mais frio (julho); do mês mais quente (janeiro); das estações 
do ano; diferença entre temperatura máxima e mínima do ano; de julho e de janeiro; do verão e do inverno; desvio padrão das temperaturas mínima e máxima.

Para o cálculo das temperaturas dos pontos de coleta, foram usadas regressões lineares múltiplas. Esses modelos de regressão foram elaborados e apresentados a partir dos dados climáticos de várias redes de estações meteorológicas da região sul do país - rede do IAPAR, do SIMEPAR, da EPAGRI, da FEPAGRO, do $8^{\circ}$ DISME/INMET, da ANA, da EMBRAPA, de Universidades Federais e do INIA-Uruguai. Estes dados foram organizados e compilados por Wrege et al. (2011). Os cálculos foram feitos para cada mês, estação do ano e ano, calculando se as temperaturas em função da altitude, da latitude e da longitude. A altitude foi obtida, em ambiente SIG, com a sobreposição dos pontos de ocorrência da espécie ao modelo numérico do terreno - MNT (modelo de altitude) (Weber \& Hasenack, 2000), utilizando uma função do ArcGIS que extrai valores de camadas no formato 'raster', a partir de um conjunto de pontos georreferenciados de ocorrência, a função 'Extract values to points'.

No caso das demais variáveis climáticas, foram geradas camadas utilizando a técnica de krigagem indicatriz, exportando os mapas gerados para o formato 'raster'. Do mesmo modo, utilizando a função 'Extract values to points', obteve-se os valores das variáveis para cada ponto.

\section{Análises estatísticas (ACP e Agrupamento)}

Os 23 parâmetros climáticos foram submetidos à Análise Multivariada de Componentes Principais (ACP). A ACP faz uma transformação linear de todas as variáveis originais em novas variáveis, de tal modo que a primeira nova variável computada seja responsável pela maior parte da variação possível, existente no conjunto de dados, a segunda pela maior variação possível restante e, assim por diante, até que toda a variação do conjunto tenha sido avaliada.

As variáveis climáticas que foram discriminadas na ACP foram utilizadas para compor a análise de agrupamento ou de cluster, cuja análise tem por objetivo agrupar indivíduos em um número restrito de grupos ou classes homogêneas. O critério de agrupamento é uma medida de similaridade ou de distância estatística entre os elementos de uma matriz " $\mathrm{x}$ " (Johnson \& Wichern, 1982). Essas medidas constituem na entrada de vários algoritmos e definem uma função dos valores dos vetores representativos dos elementos de $X$, para os quais se calcula uma medida de similaridade ou distância.

$\mathrm{Na}$ análise de cluster foi utilizado o método Ward, que consiste em um procedimento de agrupamento hierárquico no qual a medida de similaridade usada para juntar agrupamentos é calculada como a soma de quadrados entre os dois agrupamentos feita sobre todas as variáveis. Esse método tende a resultar em agrupamentos de tamanhos aproximadamente iguais devido a sua minimização da variação interna. Para extrair os grupos do dendrograma, primeiramente foram identificados os grandes grupos, geralmente poucos numerosos e, depois, os grupos menores (ou subgrupos). A distribuição geográfica também foi um elemento direcionador, pois evidencia a coerência da distribuição espacial dos grupos formados.

\section{Plotagem dos dados com os grupos formados}

Cada registro de ocorrência da erva-mate utilizado foi discriminado por cores, de acordo o pertencimento ao grupo formado pela análise de agrupamento e os registros foram plotados no mapa planialtimétrico. Para a interpretação dos resultados, ou seja, para referenciar os locais onde os grupos estão localizados, foram consideradas as unidades geomorfológicas e as regiões bioclimáticas (Golfari et al., 1978).

\section{Diferenças significativas entre os grupos formados (Kruskal Wallis)}

Para verificar as diferenças significativas existentes entre os diferentes grupos climáticos, as variáveis climáticas que foram utilizadas para compor os grupos foram submetidas ao teste $\mathrm{F}(p<0,05)$, entretanto, como foi verificado que o teste Curtose esteve fora do intervalo -2 a +2 , ficou claro que as variáveis não apresentaram distribuição normal. Devido à falta de 
normalidade, optou se pela aplicação do teste não paramétrico de Kruskal Wallis, nível de significância de $p<0,05$. Neste teste, a visualização das diferenças entre os grupos foi baseada na interpretação dos gráficos Box Plot (caixa e bigodes), onde as distribuições dos dados estão em quartis, sendo que a média fica destacada, bem como os valores atípicos. As caixas têm linhas horizontais denominadas "bigodes", que indicam a variabilidade fora dos quartis superiores e inferiores e todos os pontos fora dessas linhas, "bigodes", são considerados valores atípicos. Quando os flancos das caixas são sobrepostos aos outros flancos das outras caixas considera-se que não há diferenças entre os grupos.

\section{RESULTADOS E DISCUSSÃO}

A composição da base de dados totalizou 195 ocorrências (pontos)de erva-mate, com as coordenadas geográficas, distribuídos da seguinte forma:80 para o Paraná, 61 para Santa Catarina e 54 para o Rio Grande do Sul. Este é o maior banco que se tem notícia sobre a espécie no Brasil.

As variáveis climáticas que explicam a maior porcentagem da variação existente nos primeiros componentes principais foram: altitude $(\mathrm{m})$, coeficiente de variação da chuva, isotermalidade, NHF7 (número de horas por ano com temperatura abaixo de $7^{\circ} \mathrm{C}$ ), risco de geada (\%), precipitação de verão $(\mathrm{mm})$, precipitação de inverno $(\mathrm{mm})$, temperatura mínima de inverno $\left({ }^{\circ} \mathrm{C}\right)$,temperatura máxima de verão $\left({ }^{\circ} \mathrm{C}\right)$, diferença entre as temperaturas médias das máximas do ano e as médias das mínimas do ano $\left({ }^{\circ} \mathrm{C}\right)$, diferença entre as médias das temperaturas máximas do verão e as médias das temperaturas mínimas de verão. Todas as variáveis climáticas em seus valores máximos, mínimos e médios apresentaram diferenças entre os grupos (Tabela 1, Figura 1).

A partir da análise de agrupamento, dois grupos climáticos bem definidos foram identificados: o grupo A e o B.O grupo A, foi também dividido nos subgrupos A1, A21 e A22 com 36, 63 e 32 ocorrências, respectivamente. O grupo B foi composto por 56 ocorrências. Os grupos foram distribuídos espacialmente da seguinte forma: o grupo A1 predomina na porção norte, noroeste e oeste do Paraná e também de Santa Catarina; o A21 encontra-se na porção centro Sul do Paraná e uma porção mais restrita, entre a Serra do Mar e a Serra Geral, em Santa Catarina; o A22 na porção central e sudeste de Santa Catarina, e o Grupo B predomina em zonas dos planaltos do Rio Grande do Sul e serras do sudeste gaúcho (Figura 2). De acordo com as regiões bioclimáticas de Golfari et al. (1978), a erva-mate ocorre, naturalmente, em altitudes entre 0 a $1.500 \mathrm{~m}$, temperatura média anual entre 12 e $24^{\circ} \mathrm{C}$, com geadas frequentes a raras, precipitação média anual entre 1.100 a 2.000 mm. Os tipos climáticos são Cfa e Cwa da classificação de Köppen, com temperatura média anual de 20 a $23^{\circ} \mathrm{C}$, ocupando altitudes entre 500 a $1.500 \mathrm{~m}$ com precipitação média anual em torno de $1.500 \mathrm{~mm}$.

Neste trabalho, as áreas onde a erva-mate ocorre, naturalmente, no sul do país, situam se entre 64 a $1.390 \mathrm{~m}$, com um valor médio de 723 metros. A temperatura mínima média de inverno vai de 5,3 a $12,9{ }^{\circ} \mathrm{C}$, a temperatura máxima média de verão de 23 a $32{ }^{\circ} \mathrm{C}$, o risco de geada varia entre 60 a 100\% e o número de horas de frio entre um somatório mínimo de 27 a $514 \mathrm{~h}$. A precipitação total anual, de acordo com os registros verificados no Atlas Climático do Sul do Brasil, varia desde 1200 a 2400 mm (Wrege et al., 2011). Assim, os dados obtidos neste trabalho se assemelham aos dados obtidos por Golfari et al. (1978).

O clima é significativamente distinto para os diferentes grupos climáticos formados (A1, A21, A22 e B). A precipitação de verão é mais elevada no subgrupo $A 1$, intermediária no $A 21$ e mais baixa no grupo A22 e B. O coeficiente de variação da chuva é também menor no $B$, maior no A21 e intermediário no A1 e A22. Já a precipitação de inverno é mais alta no B, intermediária no A1 e A22 e mais baixa no A21. As precipitações pluviométricas de verão variaram de $448 \mathrm{~mm}$ (grupo B) a $540 \mathrm{~mm}$ (grupo A1) e a de inverno foi o contrário, de $297 \mathrm{~mm}$ (grupo A1) a 404 mm (grupo B), respectivamente. 

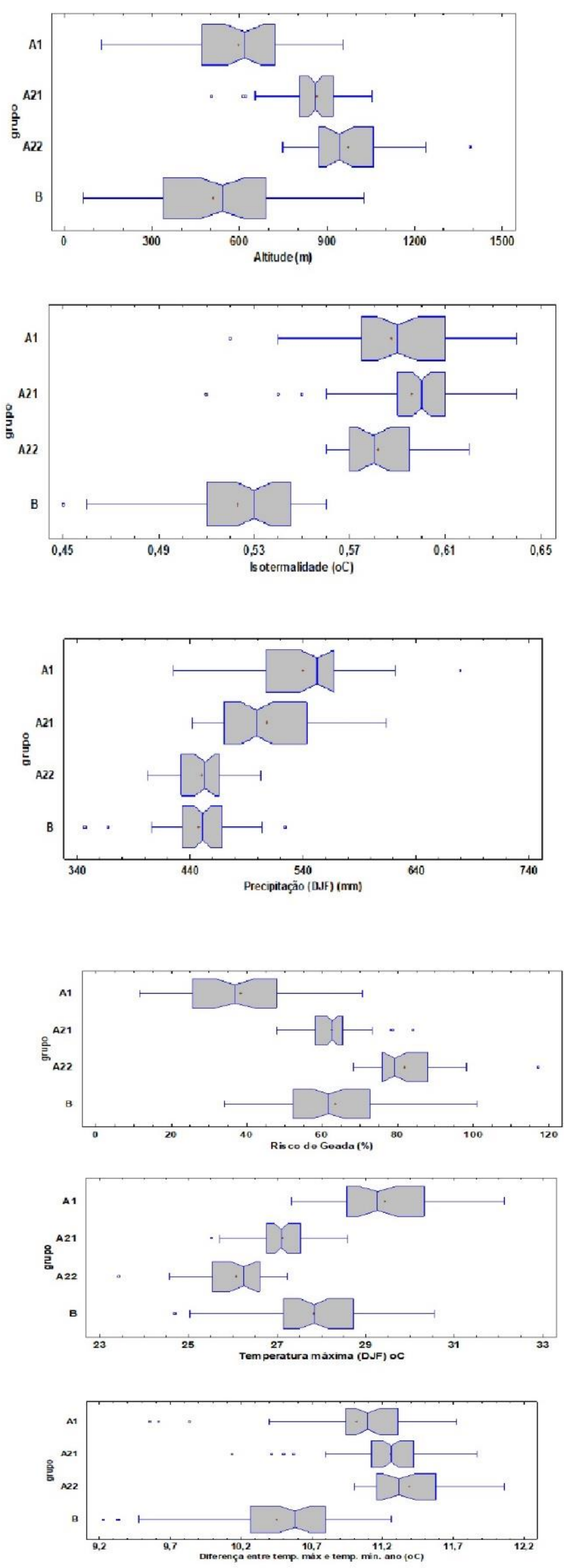

Figura 1. Gráfico Box plot da diferença entre temperatura máxima e temperatura mínima do ano.
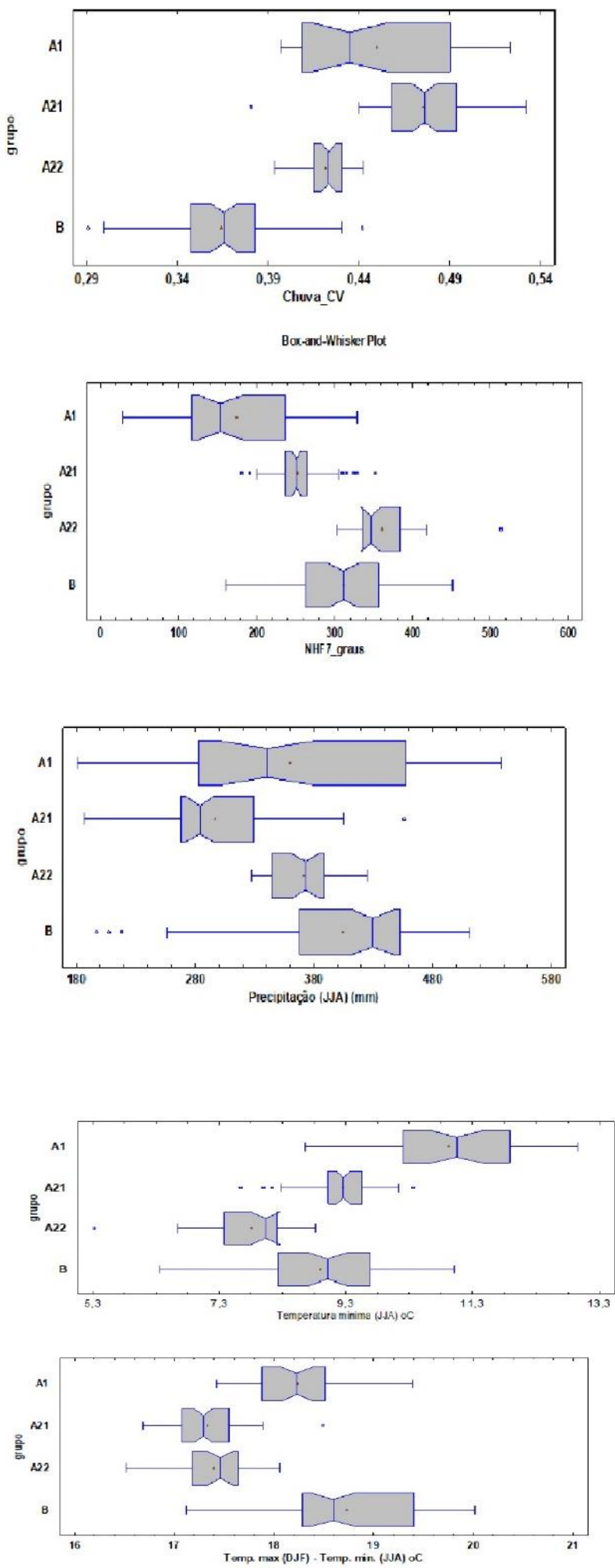
Tabela 1. Teste de Kruskal Wallis, com valor máximo, mínimo e médio, valor p e valores médios dos grupos para os parâmetros analisados.

\begin{tabular}{|c|c|c|c|c|c|c|c|c|c|}
\hline \multirow{2}{*}{ Variáveis } & \multirow{2}{*}{ Teste $K W$} & \multirow{2}{*}{$\begin{array}{l}\text { Valor } \\
\text { médio }\end{array}$} & \multirow{2}{*}{$\begin{array}{c}\text { Valor } \\
\text { mínimo }\end{array}$} & \multirow{2}{*}{$\begin{array}{l}\text { Valor } \\
\text { Max. }\end{array}$} & \multirow{2}{*}{ Valor $p$} & \multicolumn{4}{|c|}{ Valores médios dos grupos } \\
\hline & & & & & & A1 & A21 & A22 & B \\
\hline Altitude (m) & 118,28 & 723 & 64 & 1.390 & $<0,05$ & 596 & 863 & 972 & 723 \\
\hline Chuva (coef. de variação) & 132,76 & 0,42 & 0,29 & 0,53 & $<0,05$ & 0,45 & 0,48 & 0,42 & 0,36 \\
\hline Isotermalidade & 114,29 & 0,57 & 0,45 & 0,64 & $<0,05$ & 0,59 & 0,59 & 0,58 & 0,52 \\
\hline NHF7 (horas) & 104,14 & 271,5 & 28,6 & 514 & $<0,05$ & 175 & 253 & 361 & 312 \\
\hline Risco de geada (\%) & 97,7 & 61 & 12 & 100 & $<0,05$ & 38 & 63 & 82 & 64 \\
\hline Precipitação de verão (mm) & 87,57 & 487 & 346 & 679 & $<0,05$ & 540 & 508 & 450 & 448 \\
\hline Precipitação de inverno (mm) & 63,14 & 353 & 181 & 538 & $<0,05$ & 360 & 297 & 371 & 404 \\
\hline Temp. mínima inverno $\left({ }^{\circ} \mathrm{C}\right)$ & 98,79 & 9 & 5 & 13 & $<0,05$ & 11 & 9 & 8 & 9 \\
\hline Temp. máxima de verão $\left({ }^{\circ} \mathrm{C}\right)$ & 106,87 & 28 & 23 & 32 & $<0,05$ & 29 & 27 & 26 & 28 \\
\hline $\begin{array}{l}\text { Dif. entre as temp. médias das } \\
\text { máximas do ano e as médias das } \\
\text { mínimas do ano }\left({ }^{\circ} \mathrm{C}\right)\end{array}$ & 100,50 & 10,9 & 9,2 & 12 & $<0,05$ & 11 & 11 & 11 & 10 \\
\hline $\begin{array}{l}\text { Dif. entre as médias das temp. } \\
\text { máximas do verão e as médias das } \\
\text { temp. mínimas de inverno }\left({ }^{\circ} \mathrm{C}\right) .\end{array}$ & 126,5 & 17,9 & 16,5 & 20 & $<0,05$ & 18 & 17 & 17 & 19 \\
\hline
\end{tabular}

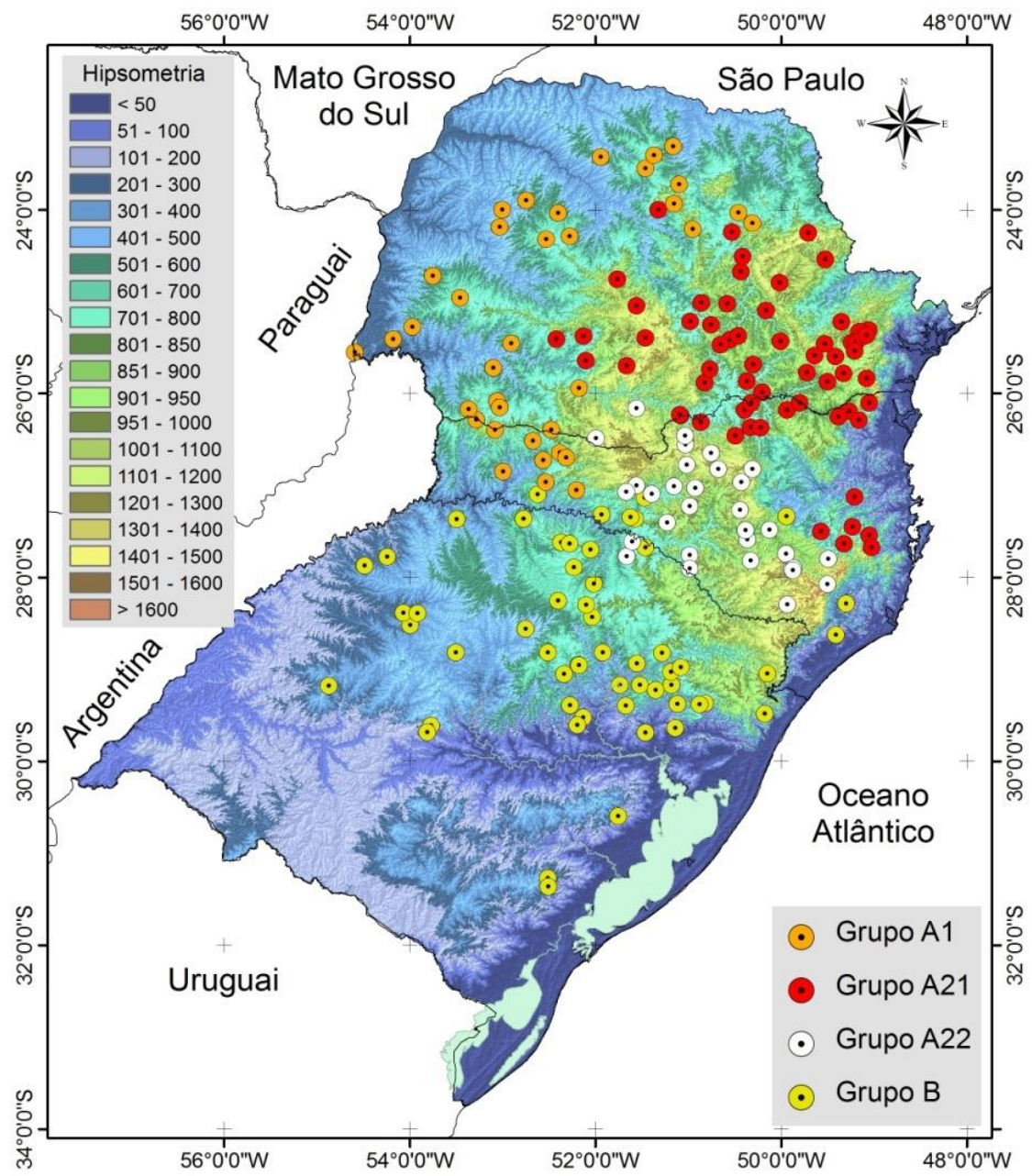

Figura 2. Grupos climáticos semelhantes de I. paraguariensis na região sul do Brasil. 
Quanto à localização geográfica dos grupos, o grupo B predomina no Rio Grande do Sul, porção mais meridional da região Sul. O clima do Rio Grande do Sul é Temperado do tipo Subtropical, classificado como Mesotérmico Úmido (classificação de Köppen). Devido à sua posição geográfica, apresenta grandes diferenças em relação ao Brasil. A latitude reforça as influências das massas de ar oriundas da região polar e da área tropical continental e Atlântica (Rio Grande do Sul, 2019).

Já o grupo A1 se situa na porção mais setentrional da região sul, em área de transição entre o clima tropical e o temperado e também nas partes mais baixas do oeste de Santa Catarina. Apresenta maior precipitação de verão e menor de inverno, como seria de se esperar para esta área de transição climática.

O grupo B também apresenta a mais baixa isotermalidade dentre os grupos, enquanto que para o número de horas de frio, o risco de geadas, a temperatura mínima de inverno e a máxima de verão apresentam valores intermediários. Este é o grupo situado em maior latitude e com tendência ao comportamento de clima mais temperado, com menor precipitação no verão e maior no inverno.

As altitudes são mais baixas no $A 1$ e no $B$, o que é facilmente identificado no mapa hipsométrico (Figura 1), são intermediárias no A21 e maiores no A22, situado no Planalto Meridional de Santa Catarina. Devido à maior altitude conjugada a latitudes intermediárias, o grupo A22 é o grupo mais frio de todos, pois sabe se que a altitude apresenta relação direta com a temperatura. Para Santa Catarina, o gradiente térmico médio, de acordo com Fritzsons et al. $(2016,2018)$, utilizando o conjunto de todas as estações meteorológicas do Estado é de $-1^{\circ} \mathrm{C} / 213 \mathrm{~m}$, o que equivale a uma redução de, aproximadamente, $0,48^{\circ} \mathrm{C}$ a cada 100 metros de altitude.

Além das maiores altitudes, o grupo A2 apresenta o maior número de horas de frio e maior porcentagem de risco de geadas e, consequentemente, as menores temperaturas mínimas de inverno e os valores mais baixos das temperaturas máximas de verão. Neste agrupamento também predomina o clima Cfb e a FOM (Floresta Ombrófila Mista). As precipitações de inverno e de verão apresentam valores intermediários, bem como os coeficientes de variação das precipitações.

Já em oposição ao grupo A2, o grupo A1 apresenta os mais baixos valores de horas de frio, altitude, risco de geada, e a maiores temperaturas mínima e máxima. Desta forma, a região desse grupo apresenta um clima mais quente ( $\mathrm{Cfa}$ ).

A somatória do número de horas de frio (NHF7) foi também um critério discriminante na análise estatística, embora não tenha sido encontrada informação na literatura que afirme que a erva-mate necessita de horas de frio para florescer ou ser cultivada. Neste trabalho, na área de estudo encontrou-se um mínimo de 175 NHF no A1 e, um máximo, de 361 NHF no A22.

A ocorrência de geadas é uma variável importante para a definição de zonas climáticas, onde a diferença entre os ecossistemas tropicais e temperados ficam mais evidentes, bem como a distribuição e a diversidade de espécies (Alvares et al., 2018). A região situada entre o sul do Paraná e o norte do Rio Grande do Sul é a de maior risco de geada, maior que 50\%, o que significa que considerando um período de dez anos, em cinco anos há ocorrência de geadas, principalmente nos municípios de maior altitude. Já na região costeira e nos vales de rios os riscos diminuem em função da menor altitude e maior umidade. Entretanto, na Metade Sul do Rio Grande do Sul, mesmo em altitudes menores, o risco de ocorrência de geadas é alto devido à latitude (Wrege et al., 2018). Neste trabalho, o risco de ocorrência de geadas variou desde 38\% (grupo A1) até $82 \%$ (grupo A22). O grupo A1, teve a maior média de temperatura mínima $\left(11^{\circ} \mathrm{C}\right)$ e também de temperatura máxima $\left(29^{\circ} \mathrm{C}\right)$, enquanto o grupo $\mathrm{A} 22$, apresentou as menores médias, tanto da temperatura mínima, quanto da temperatura máxima. Deve se observar que, além de estar situado mais ao norte e também no oeste de Santa Catarina, o grupo A1 apresenta a menor altitude média do grupo $(596 \mathrm{~m})$, enquanto que o grupo A22, apresenta a maior altitude média (972m).

No Paraná, o grupo A1 predomina no chamado "Terceiro Planalto Paranaense", que é a região próxima ao Trópico de Capricórnio, a mais quente do estado e de transição climática 
entre a região tropical e subtropical. Em Santa Catarina, este grupo está localizado no Planalto do Rio Uruguai e Planalto dos Campos Gerais. No Paraná, observando o mapa de fitogeográfico (Maack, 1981) e o mapa dos agrupamentos formados (Figura 1), verifica se que o grupo A1 ocorre tanto na Floresta Ombrófila Mista (FOM) ou floresta de araucária, quanto na Floresta Estadual Semi Decidual e, também, nos Campos Naturais do Paraná, embora não tenham sido encontrados registros nas áreas de Cerrado (Savana) e na Floresta Ombrófila Densa. Os tipos climáticos representantes deste grupo são o Cfa e Cfb (Classificação de Koeppen).

O grupo A21 se situa, predominantemente, no Primeiro e Segundo Planaltos do Paraná, mas também no nordeste de Santa Catarina, de forma contígua aos grupos do Paraná, embora em Santa Catarina apresente também outra localização isolada, na porção ocidental da Serra do Mar até os flancos da Serra Geral. Este grupo não ocorre no Rio Grande do Sul. A vegetação predominante nessas regiões é a da Floresta Ombrófila Mista e o clima é o Cfb (Classificação de Koeppen).

O grupo A22 predomina no Planalto Meridional de Santa Catarina sob rochas do Grupo Serra Geral: basaltos, basalto andesito, riodacitos e riolitos, de filiação tholeiítica, com arenitos intercalados e lentes vulcano-sedimentares (Wildner et al., 2014). O clima Cfb predomina na região.

Com base na sobreposição dos pontos de ocorrência dos grupos A21 e A22ao mapa fitogeográfico de Klein (1978) e ao inventário de Gasper et al. (2013), em Santa Catarina, conclui-se que a erva-mate ocorre em todas as formações do estado (Floresta Ombrófila Mista, Floresta Estacional Semidecidual e Campos), exceto na Formação Litorânea. Porém, na literatura científica, existe relato da presença de erva-mate na vegetação de restinga da planície costeira, em Jaguaruna, Santa Catarina (Santos et al., 2017).

O grupo $\mathrm{B}$ é distinto do grupo $\mathrm{A}$ e, consequentemente, dos demais, e ocorre numa situação mais específica. Esse grupo predomina em zonas dos planaltos do Rio Grande do Sul (Médio e Campos de Cima, Alto Uruguai, Missões) e também nas serras do sudeste gaúcho. $O$ grupo ocorre, predominantemente, no Rio Grande do Sul e com alguns exemplares em Santa Catarina, na Floresta Ombrófila Mista. Está presente tanto no bioma Pampa como no bioma da Mata Atlântica, nas seguintes formações: Estepes (Campos), Floresta Estacional Decidual e Semidecidual e Floresta Ombrófila Mista (Cordeiro \& Hasenack, 2009).

Assim, verifica se que a área de domínio da erva-mate se expande além daquela de abrangência da floresta de araucária (FOM), pois a espécie ocorre no clima Cfb, clima típico da Floresta Ombrófila Mista, no Cfa e também no Cwb, de acordo com Rotta \& Oliveira (2007). O Cwb é definido como Clima subtropical com inverno seco (com temperaturas inferiores a $18^{\circ} \mathrm{C}$ ) e verão quente (com temperaturas superiores a $22^{\circ} \mathrm{C}$ ) e predomina no Estado de São Paulo, nas regiões serranas do centro e sul de Minas Gerais e no norte, nas serras do Espinhaço e Cabral (Antunes, 1986), no sudoeste do Espírito Santo, do Rio Paraíba no Rio de Janeiro e sul do Mato Grosso do Sul.

Há também estudos que relatam ocorrência da erva-mate também na Floresta Ombrófila Densa Montana (Signor et al., 2015). Esta informação corrobora com as anteriores revelando a ampla área de ocorrência e forte plasticidade adaptativa da erva-mate. A plasticidade adaptativa pode ser definida como um fator importante para explicar a distribuição e abundância das espécies em habitats com diferentes níveis de variação e heterogeneidade ambiental e tem sido apontada como responsável pela manutenção, aumento ou redução da diversidade (Campos et al., 2013).

As diferenças climáticas encontradas na região de ocorrência natural da erva-mate indicam que uma ampla variabilidade genética poderá ser encontrada nas populações naturais, o que contribui para adaptação da espécie em diferentes condições edafoclimáticas. A utilização eficiente desse recurso genético só será possível com esforço maior na caracterização ambiental e genética de suas populações naturais.

Todos os grupos estão sobre solos desenvolvidos sob diversas litologias (Serviço Geológico do Brasil, 2008). 
Para programas de conservação e melhoramento genético, amostragens de sementes, propágulos e pólen, bem como para a conservação in situ, as quatro zonas climáticas devem ser priorizadas com a finalidade de manutenção e representação da diversidade genética da espécie. No melhoramento genético o foco é aumentar a frequência de alelos favoráveis para alguns caracteres (Freitas et al., 2012), portanto os materiais poderão ser plantados conjuntamente das quatro zonas e com réplicas em cada ambiente (zonas). Para conservação genética sugere-se estabelecer bancos ativos de germoplasma com as populações em cada zona, no mesmo local de ocorrência (zona). A mistura das populações para conservação também deve ser sugerida em consequência das mudanças climáticas e identificação de novas zonas de adaptação da espécie no futuro.

\section{CONCLUSÃO}

A metodologia utilizada se mostrou favorável e pode ser aplicada também a outras espécies.

As análises efetuadas permitem confirmar que a erva mate ocorre em climas diferentes, em distintos substratos litológicos e nas mais diversas tipologias de formações vegetais.

Foram encontrados quatro grupos climáticos distintos e estes diferem, significativamente, em todos os parâmetros climáticos analisados (temperaturas, horas de frio, porcentagem de geadas, isotermalidade e precipitações).

As diferenças climáticas encontradas na região de ocorrência da erva-mate podem indicar a possibilidade de uma ampla variabilidade nas populações naturais da erva mate, o que contribui para adaptação da espécie em diferentes condições edafoclimáticas.

\section{REFERÊNCIAS}

Alvares, C. A., Sentelhas, P. C., \& Stape, J. L. (2018). Modeling monthly meteorological and agronomic frost days, based on minimum air temperature, in Center-Southern Brazil. Theoretical and Applied Climatology, 134(1-2), 177-191. http://dx.doi.org/10.1007/s00704-017-2267-6.

Antoniazzi, M. S., Rocha, L. D., Souza, E. L., Guerra, D., Silva, D. M., \& Redin, M. (2018). Análise da cultura da erva-mate como alternativa social, econômica e ambiental para comunidades rurais. Extensão em Foco, 1(15), 1. http://dx.doi.org/10.5380/ef.v1i15.54494.

Antunes, F. Z. (1986). Caracterização climática do estado de Minas Gerais: climatologia agrícola. Informe Agropecuário, 12, 9-13.

Biota. (1999). Sistema de Informação Ambiental do Programa Biota/FAPESP. Recuperado em 25 de setembro de 2017, de http://www.biotasp.org.br/sia/

Campos, V. A., Oda, F. H., Juen, L., Barth, A., \& Dartora, A. (2013). Composição e riqueza de espécies de anfíbios anuros em três diferentes habitat em um agrossistema no Cerrado do Brasil central. Biota Neotropica, 13(1), 124-132. http://dx.doi.org/10.1590/S1676-06032013000100014.

Carvalho, P. E. R. (2003). Espécies arbóreas brasileiras (Vol. 1). Brasília: Embrapa Informação Tecnológica.

Cordeiro, J. L. P., \& Hasenack, H. (2009). A cobertura vegetal atual do Rio Grande do Sul. In Brasil, Campos sulinos: conservação e uso sustentável da biodiversidade (pp. 285-299). Brasília: MMA.

Freitas, J. P. X., Oliveira, E. J., Jesus, O. N., Cruz Neto, A. J., \& Santos, L. R. (2012). Formação de população base para seleção recorrente em maracujazeiro-amarelo com uso de índices de seleção. Pesquisa Agropecuária Brasileira, 47(3), 393-401. http://dx.doi.org/10.1590/S0100-204X2012000300011.

Fritzsons, E., Mantovani, L. E., \& Wrege, M. S. (2016). Relação entre altitude e temperatura: uma contribuição ao zoneamento climático no estado de Santa Catarina, Brasil. Revista Brasileira de Climatologia, 18, 1. http://dx.doi.org/10.5380/abclima.v18i0.39471.

Fritzsons, E., Wrege, M. S., \& Mantovani, L. E. (2018). Climatic aspects related to the distribution of Brazilian pine in the state of Santa Catarina. Floresta, 48(4), 503-512. http://dx.doi.org/10.5380/rf.v48i4.53272.

Gasper, A. L., Uhlmann, A., Sevegnani, L., Lingner, D. V., Rigon-Júnior, M. J., Verdi, M., Stival-Santos, A., Dreveck, S., Sobral, M., \& Vibrans, A. C. (2013). Floristic and forest inventory of santacatarina: species of seasonal deciduous forests. Rodriguésia, 64(3), 427-443. http://dx.doi.org/10.1590/S217578602013000300001. 
Golfari, L., Caser, R. L., \& Moura, V. P. G. (1978). Zoneamento ecológico esquemático para reflorestamento no Brasil (Série Técnica, No. 11). Belo Horizonte: PRODEPEF, PNUD/FAO/IBDF/BRA-45.

Howe, G. T., Aitken, S. N., Neale, D. B., Jermstad, K. D., Wheeler, N. C., \& Chen, T. H. H. (2003). From genotype to phenotype: unraveling the complexities of cold adaptation in forest trees. Canadian Journal of Botany, 81(12), 1247-1266. http://dx.doi.org/10.1139/b03-141.

Johnson, R. A., \& Wichern, D. W. (1982). Applied multivariate statistical analysis. Madison: Prentice Hall International.

Klein, R. M. (1978). Mapa fitogeográfico do Estado de Santa Catarina. In R. Reitz (Ed.), Flora Ilustrada Catarinense. V parte: mapa fitogeográfico. Itajaí: Herbário Barbosa Rodrigues.

Luedeling, E. (2012). Climate change impacts on winter chill for temperate fruit and nut production: a review. Scientia Horticulturae, 144, 218-229. http://dx.doi.org/10.1016/j.scienta.2012.07.011.

Maack, R. (1981). Geografia física do Estado do Paraná. Rio de Janeiro: José Olympio.

Maccari, A. J., \& Santos, A. P. R. (2000). Produtos alternativos e desenvolvimento da tecnologia Industrial da cadeia produtiva de erva-mate. Curitiba: MTC/CNPQ/PADCT.

Martins, K., Gugger, P. F., Llanderal-Mendoza, J., González-Rodríguez, A., Fitz-Gibbon, S. T., Zhao, J. L., Rodriguez-Correa, H., Oyama, K., \& Sork, V. L. (2018). Landscape genomics provides evidence of climate-associated genetic variation in Mexican populations of Quercus rugosa. Evolutionary Applications, 11(10), 1842-1858. PMid:30459833. http://dx.doi.org/10.1111/eva.12684.

Morellato, L. P. C. (2007). A pesquisa em fenologia na América do Sul e suas perspectivas atuais. In G. M. Rego, R. R. B. Negrelle \& L. P. C. Morellato (Eds.), Fenologia: ferramenta para conservação, melhoramento e manejo de recursos vegetais arbóreos (pp. 37-48). Colombo: Embrapa Florestas.

Reissmann, C. B., Radomski, M. I., \& Quadros, R. M. B. (1999). Chemical composition of Ilex paraguariensis St. Hil. under different management conditions in seven localities of Paraná State. Brazilian Archives of Biology and Technology, 42(2), http://dx.doi.org/10.1590/S151689131999000200009.

Resende, M., Santana, D. P., \& Curi, N. (1988). Pedologia e fertilidade do solo: interação e aplicações. Lavras: Escola Superior de Agricultura de Lavras.

Rio Grande do Sul. Secretaria do Planejamento Orçamento e Gestão. (2019). Atlas sócio econômico do Rio Grande do Sul. Recuperado em 15 de fevereiro de 2019, de https://atlassocioeconomico.rs.gov.br/clima-temperatura-e-precipitacao

Rotta, E., \& Oliveira, Y. M. (2007). Cultivo da erva-mate: distribuição geográfica. Recuperado em 25 de setembro de 2017, de http://www.sistemasdeproducao.cnptia.embrapa.br/FontesHTML/Erva-mate

Santin, D., Benedetti, E., Kaseker, J., Bastos, M., Reissmann, C., Wendling, I., \& Barros, N. (2013). Nutrição e crescimento da erva-mate submetida à calagem. Ciência Florestal, 23(1), 55-66. http://dx.doi.org/10.5902/198050988439.

Santos, R., Elias, G. A., Guislon, A. V., \& Zanoni, I. Z. (2017). Vegetação arbustivo-arbórea em uma restinga de Jaguaruna, litoral sul do Estado de Santa Catarina, Brasil. Revista Ambiente \& Água, 12(1), 99-111. http://dx.doi.org/10.4136/ambi-agua.1952.

Serviço Geológico do Brasil - CPRM. (2008). Mapa geológico do Estado do Rio Grande do Sul escala 1:750.000. Recuperado em 25 de janeiro de 2019, de http://geosgb.sa.cprm.gov.br/

Signor, P., Gomes, G. S., \& Watzlawick, L. F. (2015). Produção de erva-mate e conservação de Floresta com Araucária. Pesquisa Florestal Brasileira, 35(83), 199-208. http://dx.doi.org/10.4336/2015.pfb.35.83.898.

Vieira, A. R. R., Suertegaray, C. E. O., Heldwein, A. B., Maraschin, M., \& Silva, A. L. (2003). Influência do microclima de um sistema agroflorestal na cultura da erva mate (Ilex paraguariensis St. Hil.). Revista Brasileira de Agrometeorologia, 11(1), 91-97.

Wang, T., O'Neill, G. A., \& Aitken, S. N. (2010). Integrating environmental and genetic effects to predict responses of tree populations to climate. Ecological Applications, 20(1), 153-163. PMid:20349837. http://dx.doi.org/10.1890/08-2257.1.

Weber, E., \& Hasenack, H. (2000). Avaliação de áreas para instalação de aterro sanitário através de análises em SIG com classificação contínua dos dados. Porto Alegre: UFRGS.

Wildner, W., Camozzato, E., Toniolo, J. A., Binotto, R. B., Iglesias, C. M. F., \& Laux, J. H. (2014). Mapageológico do estado de Santa Catarina (Escala 1:500.000). Porto Alegre: CPRM, Programa Geologia do Brasil. Subprograma de Cartografia Geológica Regional. 
Wrege, M. S., Fritzsons, E., Soares, M. T. S., Prela-Pântano, A., Steinmetz, S., Caramori, P. H., Radin, B., \& Pandolfo, C. (2018). Risco de ocorrência de geada na região Centro-Sul do Brasil. Revista Brasileira de Climatologia., 22, 524-553. http://dx.doi.org/10.5380/abclima.v22i0.57306.

Wrege, M. S., Steinmetz, S., Reisser, J. R. C., \& Almeida, I. R. (2011). Atlas climático da região sul do Brasil: estados do Paraná, Santa Catarina e Rio Grande do Sul (1. ed., Vol. 1). Pelotas: Embrapa.

Contribuição dos autores: EF: conceituação, análise dos dados, investigação e, supervisão e escrita, MSW: software, validação e escrita, MTSS e AVA e VAS: investigação e escrita, AGS e FM: software e validação. 